Functional Nanostructured Materials (including low-D carbon)

\title{
Citrate-coated, size-tunable octahedral platinum \\ nanocrystals: a novel route for advanced electrocatalysts
}

Mauro Moglianetti, Jose Solla-Gullon, Paolo Donati, Deborah Pedone, Doriana Debellis, Teresa

Sibillano, Rosaria Brescia, Cinzia Giannini, Vicente Montiel, Juan M. Feliu, and Pier Paolo Pompa

ACS Appl. Mater. Interfaces, Just Accepted Manuscript • DOI: 10.1021/acsami.8b11774 • Publication Date (Web): 08 Nov 2018

Downloaded from http://pubs.acs.org on November 15, 2018

\section{Just Accepted}

"Just Accepted" manuscripts have been peer-reviewed and accepted for publication. They are posted online prior to technical editing, formatting for publication and author proofing. The American Chemical Society provides "Just Accepted" as a service to the research community to expedite the dissemination of scientific material as soon as possible after acceptance. "Just Accepted" manuscripts appear in full in PDF format accompanied by an HTML abstract. "Just Accepted" manuscripts have been fully peer reviewed, but should not be considered the official version of record. They are citable by the Digital Object Identifier (DOI@). "Just Accepted" is an optional service offered to authors. Therefore, the "Just Accepted" Web site may not include all articles that will be published in the journal. After a manuscript is technically edited and formatted, it will be removed from the "Just Accepted" Web site and published as an ASAP article. Note that technical editing may introduce minor changes to the manuscript text and/or graphics which could affect content, and all legal disclaimers and ethical guidelines that apply to the journal pertain. ACS cannot be held responsible for errors or consequences arising from the use of information contained in these "Just Accepted" manuscripts. 


\title{
Citrate-coated, size-tunable octahedral platinum
}

\section{nanocrystals: a novel route for advanced electrocatalysts}

\author{
Mauro Moglianetti ${ }^{1 *}$, José Solla-Gullón ${ }^{2 *}$, Paolo Donati ${ }^{1}$, Deborah Pedone ${ }^{1,3}$, \\ Doriana Debellis ${ }^{4}$, Teresa Sibillano ${ }^{5}$, Rosaria Brescia ${ }^{4}$, Cinzia Giannini' ${ }^{5}$, Vicente \\ Montiel$^{2}$, Juan M. Feliu², and Pier Paolo Pompa ${ }^{1,6}$ \\ 1. Nanobiointeractions \& Nanodiagnostics, Center for Bio-Molecular Nanotechnologies, \\ Istituto Italiano di Tecnologia, Via Barsanti - 73010 Arnesano (Lecce), Italy \\ 2. Institute of Electrochemistry, University of Alicante, Apdo. 99, E-03080, Alicante, Spain
}

3. University of Salento, Department of Engineering for Innovation, Via per Monteroni, Lecce, Italy

4. Electron Microscopy Facility, Istituto Italiano di Tecnologia, Via Morego 30 - 16163 Genova, Italy

5. Institute of Crystallography, National Research Council (IC-CNR), Via Amendola 122/O, 70126 Bari

6. Nanobiointeractions \& Nanodiagnostics, Istituto Italiano di Tecnologia (IIT), Via Morego, 30 - 16163, Genova, Italy.

Email: mauro.moglianetti@iit.it, jose.solla@ua.es 


\begin{abstract}
The development of green and scalable syntheses for the preparation of size- and shape-controlled metal nanocrystals is of high interest in many areas, including catalysis, electrocatalysis, nanomedicine, and electronics. In this work, a new synthetic approach based on the synergistic action of physical parameters and reagents produces size-tunable octahedral Pt nanocrystals, without the use of catalyst-poisoning reagents and/or difficult-to-remove coatings. The synthesis requires sodium citrate, ascorbic acid, and fine control of the reduction rate in aqueous environment. Pt octahedral nanocrystals with particle size as low as 7 $\mathrm{nm}$ and highly developed $\{111\}$ facets have been achieved, as demonstrated by transmission electron microscopy, X-ray diffraction, and electrochemical methods. The absence of sticky molecules together with the high quality of the surface renders these nanocrystals ideal candidates in electrocatalysis. Notably, $7 \mathrm{~nm}$ bismuth-decorated octahedral nanocrystals exhibit superior performance for the electro-oxidation of formic acid in terms of both specific and mass activities.
\end{abstract}

Keywords: Pt nanocrystals, shape, citrate-coated, formic acid electrooxidation, octahedral, green synthesis 


\section{Introduction}

The shape of nanomaterials plays an important role as it strongly modulates and enhances specific properties, from improved selectivity and activity in catalytic processes to tunable interaction with light and living matter. ${ }^{1-4}$ Even though there are several methods available in the literature to obtain polyhedral nanostructures, such as cubes, tetrahedrons, and octahedrons of several noble metals, $^{5-12}$ there are few reports on the synthesis of shaped noble metal nanoparticles without the use of polymers, surfactants, organic solvents and other directing agents, which are difficult to remove after synthesis. For catalytic Pt nanocrystals, the shape plays a fundamental role as it regulates the activity and selectivity of the material in many processes, including catalysis and fuel cells. ${ }^{13-21}$ In particular, the surface structure, i.e. the specific arrangement of the atoms at the surface, is the key point determining and controlling the electrocatalytic properties of the material. $13,22-24$

Many synthetic strategies have been proposed to obtain shaped Pt nanocrystals, particularly focusing on wet chemical reaction methods. The main parameter is typically the stabilization of a facet through the use of additives. Chemical species that selectively stabilize specific facets influence the growth along specific direction, tailoring the final shape of particle. ${ }^{13,22}$ There is a long list of polymers, surfactants, inorganic salts, and small organic molecules that have been used to promote nanocrystal shape formation. ${ }^{13}$ However, the coating remaining on the nanocrystal surface also affects the catalytic properties of the material. In particular, it has been found that the most commonly used shapedirecting agents, i.e. PVP, tetradecyl trimethyl ammonium bromide, and oleylamine, are detrimental to many catalytic reactions, altering the surface properties of the material. ${ }^{13,16,25-26}$ Different procedures have been developed to remove completely the organic coating on the surface of the nanoparticles. Nevertheless, most of these treatments are time-consuming, costly, do not guarantee complete removal and, more importantly, may interfere with the surface structure and, hence, with the catalytic properties of the nanocrystals. ${ }^{27}$ 
Moreover, a recent contribution reviews the most relevant advances dealing with efficient surface cleaning methodologies applied to shape-controlled metal nanoparticles, showing the challenges associated with this process. ${ }^{22}$

On the other hand, it is well-accepted that, as the particle size decreases, the proportion of $\{111\}$ and $\{100\}$ domains tends to decrease dramatically, while low coordination sites such as edges, steps, corners and kinks become predominant in the surface. ${ }^{28}$ Consequently, the possibility of designing few nanometer size octahedral Pt nanocrystals with high percentage of $\{111\}$ facet percentage represents a challenge.

Here, we show a "green" synthetic procedure and a microwave-assisted scale-up process to obtain octahedral Pt nanocrystals by using sodium citrate and ascorbic acid in aqueous environment coupled with accurate control of the reduction rate. Fine tuning of the size of the nanocrystal is obtained by modifying the precursor concentration and the seed size. Nanocrystals with size as low as 7 nm and high percentage of $\{111\}$ facets have been achieved. The so-prepared nanocrystals have been physico-chemically and electrochemically characterized. The electrocatalytic properties of these nanoparticles have been evaluated towards the electro-oxidation of formic acid. In this regard, it is well established that the use of some adatoms remarkably enhances the electrocatalytic properties of the Pt substrate. In the present work, we will show that the $7 \mathrm{~nm}$ octahedral nanocrystals fully decorated with bismuth adatoms clearly display the best performance (among the different octahedral Pt nanoparticles tested) in terms of current per unit surface area or mass in the electro-oxidation of formic acid. These findings open the way to their possible application in practical fuel cell devices. 


\title{
Materials and methods
}

\section{Experimental details}

\author{
Materials \\ Chloroplatinic acid hexahydrate BioXtra, L-ascorbic acid BioXtra, sodium citrate \\ tribasic dihydrate BioUltra, sodium borohydride, citric acid anhydrous were \\ bought from Merck/ Sigma-Aldrich and used as received.
}

\section{Nanocrystals synthesis}

Pt seed synthetic procedure

Pt seeds were synthesized by adding $55 \mu \mathrm{L}$ of hexachloroplatinic acid aqueous solution $(0.5 \mathrm{M})$ (BioXtra grade, Sigma-Aldrich) to $90 \mathrm{~mL}$ of MilliQ water at boiling temperature. After $1 \mathrm{~min}, 2.2 \mathrm{~mL}$ of a $35 \mathrm{mM}$ sodium citrate and $3 \mathrm{mM}$ citric acid aqueous solution was added, immediately followed by a quick addition of $1.1 \mathrm{~mL}$ of $22 \mathrm{mM}$ aqueous solution of $\mathrm{NaBH}_{4}$, just dissolved. After 10 min the solution was cooled to room temperature. For the synthesis of $7 \mathrm{~nm}$ octahedral nanocrystals, slightly smaller seeds were synthesized by adding the $\mathrm{NaBH}_{4}$ aqueous solution $(44 \mathrm{mM})$ to a solution immersed in ice to slow down the growth. The solution was sealed within a glass container and then abruptly transferred to a silicon oil bath already at $100{ }^{\circ} \mathrm{C}$ to obtain a quick reduction of the Pt ions, and, hence, smaller seeds.

\section{$18 \mathrm{~nm}$ octahedral Pt nanocrystal synthetic procedure}

The synthesis was performed in a sealed glass container (ACE glass pressure reactor with Teflon cap). $3 \mathrm{ml}$ of platinum nanocrystals seed (synthesized following the protocol described in the previous paragraph) were added to $87 \mathrm{ml}$ of MilliQ water. $0.11 \mathrm{~mL}$ of hexachloroplatinic acid aqueous solution $(0.5 \mathrm{M})$ was added together with $1.5 \mathrm{ml}$ of an aqueous solution of sodium citrate (35 mM) and L-ascorbic acid (70 mM). The vessel was then sealed, placed in an oil bath and brought to $105{ }^{\circ} \mathrm{C}$ in 20 minutes. The reaction was kept at these conditions for 1 hour under magnetic stirring at moderate rate. The vessel was then removed from the oil bath and left to cool under stirring for another hour.

10 and $7 \mathrm{~nm}$ octahedral Pt nanocrystals were synthesized following the protocol presented in the previous sections. $2 \mathrm{~nm}$ size seeds and lower amount of hexachloroplatinic acid hexahydrate were used to reduce the growth while keeping the control on the synthesis.

\section{$10 \mathrm{~nm}$ octahedral Pt nanocrystal synthetic procedure}

$3 \mathrm{ml}$ of platinum nanocrystals seed with average size around $2 \mathrm{~nm}$ were added to $87 \mathrm{ml}$ of MilliQ water. $54 \mu \mathrm{L}$ of hexachloroplatinic acid aqueous solution $(0.5 \mathrm{M})$ was added together with $1.5 \mathrm{ml}$ of an aqueous solution of sodium citrate (35 $\mathrm{mM}$ ) and L-ascorbic acid (70 $\mathrm{mM})$. The vessel was then sealed, placed in an oil bath and brought to $105{ }^{\circ} \mathrm{C}$ in 20 minutes. The reaction was kept at these 
conditions for 1 hour under magnetic stirring at moderate rate. The vessel was then removed from the oil bath and left to cool under stirring for another hour.

\section{$7 \mathrm{~nm}$ octahedral Pt nanocrystal synthetic procedure}

$3 \mathrm{ml}$ of platinum nanocrystals seeds solution with average size around $2 \mathrm{~nm}$ was added to $87 \mathrm{ml}$ of MilliQ water. $36 \mu \mathrm{L}$ of hexachloroplatinic acid aqueous solution $(0.5 \mathrm{M})$ was added together with $1.5 \mathrm{ml}$ of an aqueous solution of sodium citrate $(35 \mathrm{mM})$ and L-ascorbic acid $(70 \mathrm{mM})$. The vessel was then sealed, placed in an oil bath and brought to $105{ }^{\circ} \mathrm{C}$ in 20 minutes. The reaction was kept at these conditions for 1 hour under magnetic stirring at moderate rate. The vessel was then removed from the oil bath and left to cool under stirring for another hour.

\section{Scale-up of nanocrystal synthesis using Flexiwave Microwave Reactor}

\section{$18 \mathrm{~nm}$ octahedral Pt nanocrystal scale-up method}

The synthesis was performed in a microwave reactor, using the multi-vessel setup. $3 \mathrm{ml}$ of platinum nanocrystals seed with average size around $3 \mathrm{~nm}$ (synthesized following a previously developed protocol) were added to $87 \mathrm{ml}$ of MilliQ water. $110 \mu \mathrm{L}$ of hexachloroplatinic acid aqueous solution (0.5 M) was added together with $1.5 \mathrm{ml}$ of an aqueous solution of sodium citrate $(35 \mathrm{mM})$ and L-ascorbic acid (70 $\mathrm{mM})$. The 15 vessels were then sealed, placed within the microwave chamber and brought to $105^{\circ} \mathrm{C}$ in 20 minutes. The reaction was kept at these conditions for 1 hour under magnetic stirring at moderate rate.

10 and $7 \mathrm{~nm}$ diameter shaped nanocrystals were synthesized following the protocol presented in the previous sections. $2 \mathrm{~nm}$ size seeds and lower amount of hexachloroplatinic acid solution were used to reduce the growth while keeping the control on the synthesis.

\section{$10 \mathrm{~nm}$ octahedral Pt nanocrystal scale-up method}

$3 \mathrm{ml}$ of platinum nanocrystals seed with average size around $2 \mathrm{~nm}$ were added to $87 \mathrm{ml}$ of MilliQ water. $55 \mu \mathrm{L}$ of hexachloroplatinic acid aqueous solution $(0.5 \mathrm{M})$ was added together with $1.5 \mathrm{ml}$ of an aqueous solution of sodium citrate (35 $\mathrm{mM}$ ) and L-ascorbic acid (70 $\mathrm{mM})$. The 15 vessels were then sealed, placed within the microwave chamber and brought to $105{ }^{\circ} \mathrm{C}$ in 20 minutes. The reaction was kept at these conditions for 1 hour under magnetic stirring at moderate rate.

\section{$7 \mathrm{~nm}$ octahedral Pt nanocrystal scale-up method}

$3 \mathrm{ml}$ of platinum nanocrystals seed with average size around $2 \mathrm{~nm}$ were added to $87 \mathrm{ml}$ of MilliQ water. $36 \mu \mathrm{L}$ of hexachloroplatinic acid aqueous solution $(0.5 \mathrm{M})$ was added together with $1.5 \mathrm{ml}$ of an aqueous solution of sodium citrate (35 $\mathrm{mM})$ and L-ascorbic acid (70 $\mathrm{mM})$. The 15 vessels were then sealed, placed within the microwave chamber and brought to $105{ }^{\circ} \mathrm{C}$ in 20 minutes. The reaction was kept at these conditions for 1 hour under magnetic stirring at moderate rate. 


\section{Transmission electron microscopy analysis}

BF-TEM, HAADF-STEM and SAED analyses were carried out using a FEI Tecnai G2 F20 TWIN microscope, with a Schottky emitter and operated at $200 \mathrm{kV}$, Processing of SAED data was done via the PASAD plugin of Gatan Digital Micrograph. ${ }^{29}$

The lateral size of the nanocrystals was obtained by manual imposing a threshold on the HAADF-STEM images followed by automatic measurement of the Feret's diameter using the Image software. ${ }^{30}$ For the samples Pt NC18, Pt NC10 and Pt NC7, 100 particles were considered for the distribution. Only for the sample Pt NC18, exhibiting particles with an anisotropic shape characterized by more extended facets, a shape selection step was applied. In particular, particles exhibiting a triangular projection in the HAADF-STEM images were excluded, as they would systematically shift the distribution to higher values. The motivation for this choice is that the parameter of interest, to be compared with the results of WAXS analyses, is the body diameter of the NPs, which can be reliably extracted from HAADF-STEM images only for the less anisotropic particles.

HRTEM images and STEM-EDS maps were acquired using a Cs-image corrected JEOL JEM-2200FS TEM (Schottky emitter, operated at $200 \mathrm{kV}$ ), equipped with a Bruker XFlash 5060 EDS system.

VESTA 3D visualization program was employed to draw a schematic model of a truncated octahedral Pt nanocrystal. ${ }^{31}$

\section{X-ray Diffraction}

X-ray Diffraction (XRD) data were collected by a D8-Discover Bruker diffractometer, equipped with a Cu Roentgen tube $\left(\lambda \mathrm{K}_{\alpha 1}=1.54056 \AA\right.$ and $\lambda \mathrm{K}_{\alpha}$ ${ }_{2}=1.54439 \AA$ ), a Göbel mirror as primary optics, an Eulerian cradle with motorized rotation and translation movements and a scintillation detector. Data were collected in the angular range $2 \theta=5-130^{\circ}$ with a step of $0.05^{\circ}$, with a fixe angle of incidence of $5^{\circ}$.

\section{Cleaning process for the octahedral Pt nanocrystals}

The methodology used is similar to that previously employed with quasispherical Pt nanocrystals also prepared in presence of citrate..$^{32}$ In brief, a NaOH pellet ( $0.2 \mathrm{~g}$ ) was directly added to the colloidal suspension (about $10 \mathrm{ml}$ ) containing the octahedral Pt nanocrystals. The incorporation of the $\mathrm{NaOH}$ induces the destabilization of the suspension and the nanocrystals precipitate. After complete precipitation, the supernatant is discarded and the nanocrystals were washed 3-4 times with ultra-pure water.

\section{Electrochemical characterization}

For the electrochemical measurements, a VMP3 multichannel potentiostat (BioLogic) was employed. A three-electrode electrochemical cell working in a NStat configuration (one counter electrode (Pt wire), one reference electrode (a reversible hydrogen electrode (RHE) connected to the cell through a Luggin capillary) and three working electrodes working simultaneously) was used. The working electrodes were prepared by depositing a known aliquot of $4 \mu \mathrm{L}$ of the water solution containing the nanocrystals onto a glassy carbon rod $(3 \mathrm{~mm}$ diameter, Goodfellow). The electrode is then protected and dried under an $\mathrm{Ar}$ 
atmosphere until complete evaporation of the solvent. Before each experiment, the glassy carbon collector was mechanically polished with alumina and finally rinsed with ultra-pure water to eliminate impurities and previous nanocrystals.

The voltammetric characterization of the samples was performed in $0.5 \mathrm{M} \mathrm{H}_{2} \mathrm{SO}_{4}$. Formic acid electrooxidation was carried out in a solution containing $0.5 \mathrm{M}$ $\mathrm{H}_{2} \mathrm{SO}_{4}+0.5 \mathrm{M} \mathrm{HCOOH}$. All electrolyte solutions were prepared from Milli-Q ${ }^{\circledR}$ water and Merck "p.a." sulphuric and formic acid and Ar (Air Liquide N50) deaerated before use. All the experiments were made at room temperature.

\section{Co stripping experiments}

CO stripping experiments were performed by bubbling CO (Air Liquide N47) in the electrolyte $\left(0.5 \mathrm{M} \mathrm{H}_{2} \mathrm{SO}_{4}\right)$ at $0.05 \mathrm{~V}$ for $1-2 \mathrm{~min}$. The complete $\mathrm{CO}$ blockage of the surface was verified by cycling the electrode between 0.05 and $0.35 \mathrm{~V}$. Subsequently, CO was removed from the solution by bubbling Ar for at least 1520 min. Finally, adsorbed CO was electrochemically oxidized in a single sweep.

\section{Surface area determination}

The correct determination of the electroactive surface area of the Pt nanocrystals is very important because it allows properly comparing the intrinsic electrocatalytic properties of the different nanocrystals. As described in previous contribution $^{33}$, the electroactive surface area of the different Pt nanocrystals can be determined by measuring the charge involved in the so-called hydrogen UPD region and assuming $230 \mu \mathrm{C} \mathrm{cm}^{-2}$ for the total charge after the subtraction of the double layer contribution.

\section{Quantification of the $\{111\}$ surface domains at the nanocrystals}

As described in previous contributions ${ }^{34-35}$, the quantification of the $\{111\}$ surface sites at the surface of the different octahedral Pt nanocrystals was carried out by the irreversible adsorption of bismuth. Bi adsorption was achieved by contacting the electrode with an acidic solution containing $\mathrm{Bi}_{2} \mathrm{O}_{3}$ at open circuit potential. The resulting Bi coverage can be controlled by changing the $\mathrm{Bi}(\mathrm{III})$ concentration and immersion time. In the present case, maximum $\mathrm{Bi}$ coverages were achieved by using $\mathrm{Bi}_{2} \mathrm{O}_{3}$ saturated solutions and immersion times of about $2 \mathrm{~min}$. The electrode is then thoroughly rinsed with ultrapure water before being immersed at $0.05 \mathrm{~V}$ in the electrochemical cell containing a $0.5 \mathrm{M} \mathrm{H}_{2} \mathrm{SO}_{4}$ solution in which the Bi coverage is estimated. 


\section{Results and discussion}

\section{Synthetic methodology}

A new synthetic approach based on the synergistic interplay of physical parameters and reagents provides shaped nanocrystals without the use of polymeric directing agents or sticky molecules. In particular, this method produces platinum nanocrystals with size as low as $7 \mathrm{~nm}$ with octahedral shape in aqueous environment, without the use of surfactants, polymers, and other inorganic salts, using seed-growth method. The reaction does not require a complex setup and is performed in a closed vessel under temperature and warming-up rate control in the presence of two easy-to-remove reagents, namely sodium citrate and ascorbic acid (Fig. 1).

More in details, the synthesis is performed in a sealed glass container with teflon cap. To a solution of Pt nanocrystals seed, hexachloroplatinic acid aqueous solution was added together with sodium citrate and L-ascorbic acid solution. The vessel was then sealed, and brought to $105{ }^{\circ} \mathrm{C}$ in well-defined time. The reaction was kept at these conditions for 1 hour. The scale-up is obtained by using a microwave reactor equipped with the multi-vessel setup (see SI for experimental details).

Bright-field transmission electron microscopy (BF-TEM) and high-angle annular dark-field scanning TEM (HAADF-STEM) images of citrate-capped $\mathrm{Pt}$ nanocrystals of three different sizes, ranging from 7 to 18 (Pt NC7, Pt NC10, Pt NC18) are shown in Fig. 2 and S1. The nanocrystals exhibit an octahedral shape. All the samples have face-centered cubic single crystal structure, according to selected area electron diffraction (SAED) patterns (Fig. 2G). A more detailed investigation of the faceting of the nanocrystals was carried out by highresolution TEM (HRTEM) (Fig. 3). These analyses show that the most extended facets are parallel to $\{111\}$ planes, while the $\{100\}$ facets are scarcely developed, resulting in a slightly truncated octahedral shape.

A synergistic interplay of the reaction parameters, together with the presence of sodium citrate and ascorbic acid, promotes anisotropic growth altering reduction kinetics and, hence, resulting in kinetic growth conditions. ${ }^{14,}{ }^{36}$ In a recent report, it has clearly established through electrochemical experiments, Fourier Transform Infrared Spectra (FTIR) and Density Functional Theory (DFT) 
that citrate ions in aqueous solution can become simultaneously adsorbed on the $\operatorname{Pt}(111)$ surface through all three dehydrogenated carboxylic groups in bidentate configuration. ${ }^{37}$ For this reason, citrate is more favorably adsorbed on the $\operatorname{Pt}(111)$ than on the other two basal planes of platinum, providing a stabilizing effect to this crystallographic facet.

However, up to now, the aqueous synthetic protocols of Pt nanocrystals growth employing sodium citrate were unable to produce shaped nanomaterial as the presence of sodium citrate is a necessary but not sufficient condition. To obtain octahedral shape, it is crucial to finely tune the reaction conditions, the precursor concentration, and the reducing and stabilizing agents to control the growth process and drive the reaction under kinetic control. ${ }^{14,} 38$ In detail, the control of the temperature and heating rate in a closed container plays a crucial role in the formation of octahedral nanocrystals (Fig. S2). The same reaction conditions in an open reflux setup do not produce preferentially shaped nanocrystals, but spherical flower-like nanocrystals (Fig. S3-S4). This underlines the crucial role of the synergy of the reaction parameters in achieving the growth of polyhedrons. At temperatures above the threshold value of $105^{\circ} \mathrm{C}$, the reaction is under pure thermodynamic growth conditions, and platinum nanocrystals grow as spherical nanoflowers to minimize their surface energy (Fig. S5). Moreover, the heating rate during the warming-up phase plays a major role. Faster heating-up rate than the one reported leads to the loss of control on the nanocrystals growth and, hence, to the formation of flower-like nanoparticles (Fig. S6-S7). The control of reaction temperature gradient demonstrates that slow reduction conditions are crucial to get shaped octahedral Pt nanocrystals, as they give the shape-directing agents enough time to interact at the particles surface, making them more effective at producing octahedral shape. Low rate of reduction during the warming-up phase can also promote higher precursor-to-seeds ratio, a fundamental step in the shape formation. ${ }^{39}$

The oxidation state of the Pt precursors and, thus, the kinetic of reduction have also a strong effect on the nanocrystals shape. Introducing Pt(II) in the reaction vessel changes the reaction rate and leads to the formation of flower-like spherical nanoparticles (Fig. S8). 
Therefore, we have designed the conditions to move the reaction under kinetic control, operating at temperature below $105^{\circ} \mathrm{C}$ with reduced reduction rate and the presence of sodium citrate and ascorbic acid as directing agents. ${ }^{7}, 12,40-46$ Impurities also play a crucial role in promoting or impairing controlled growth of nanoparticles. Only extremely purified Pt precursors lead to the formation of octahedral shape, whilst commonly used Pt compounds without extensive purification lead to the formation of spherical-like shape (Fig. S9). This confirms that slight modifications and presence of impurities have a drastic impact in the outcome. ${ }^{43}$ We have thus defined the crucial parameters to achieve shaped nanoparticle growth, demonstrating the synergy required between the physical parameters and the reducing and stabilizing agents, to achieve control in the synthesis of shaped platinum nanoparticles. L-ascorbic acid and sodium citrate play a role in reducing the precursors and, then, in stabilizing the nanoparticles. Although it has been reported that sodium citrate can act as directing agent in the synthesis of preferentially shaped silver nanocrystals, ${ }^{47}$ in the case of platinum nanocrystals this does not represent a sufficient condition. Furthermore, from a catalytic point of view, L-ascorbic acid and sodium citrate bind only weakly to the surface of platinum nanocrystals through their carboxylic and hydroxyl groups. This is a major advantage, as they stabilize the particles in solution against aggregation, but they can easily be removed by using sodium hydroxide, as described in the SI section. In this way, clean surfaces, an extremely relevant aspect for catalysis and fuel cells application, can be effectively obtained. Furthermore, the synthesis has the requirements to be defined as "green" as it uses water as solvent and biocompatible compounds, like sodium citrate and ascorbic acid. This represents an important aspect considering the effort devoted by the scientific community to develop synthetic methods with low environmental impact. ${ }^{48}$

The method proposed here is a breakthrough towards a complete control of the experimental parameters that govern the nucleation and growth of nanoparticles. Moreover, the absence of sticky molecules on the surface, which are difficult to remove, represents a further advantage for catalysis and fuel cell applications.

The lab-based synthetic methodology developed for octahedral platinum nanocrystals has been also scaled-up, by using a microwave reactor in a closed 
reaction system. A multi-vessel setup has been employed, achieving more than half a gram of product in one hour. This represents almost a two orders of magnitude increase compared to lab-based procedure (Fig. S10).

\section{XRD analysis}

For nanocrystalline powders with reduced domain size, a major role is played by the surface atoms that, for extremely small nanocrystals, can even exceed the number of bulk atoms. Surface energies generate changes in the length of the interatomic bonds determining important strain contributions and/or surface atoms lattice reconstruction. ${ }^{49}$ This already justifies the introduction of a sizerelated lattice parameter in the Bragg equation, ${ }^{50}$ which cannot be anymore routinely applied as for conventional micrometric polycrystalline powders. For extremely small nanocrystals, a Debye function approach is preferable, with respect to traditional crystallographic method, to describe correctly the XRD patterns and derive from it the structure and microstructure of these materials. Indeed, the Debye function ${ }^{51-53}$ does not require any lattice periodicity to calculate the diffracted intensity.

The X-ray diffraction data, collected on the samples, are shown in Fig. 4. The atomic models, used in the Debye simulations, describe the Pt face-centeredcubic unit cell (space group F m -3 m) and a crystalline habit of 45x45x45 (Fig. 4a), 20x20x20 (Fig. 4b) and $15 \times 15 \times 15$ (Fig. 4c) unit cells, along the $\vec{a}, \vec{b}$ and $\vec{c}$ crystallographic axes, which correspond to a crystalline dimension of $18 \pm 2 \mathrm{~nm}$, $8 \pm 2 \mathrm{~nm}$ and $6 \pm 2 \mathrm{~nm}$, respectively (Fig. S11). These results are in close agreement, both in terms of size and shape, with the TEM analysis and further demonstrate the reduced polydispersity in size and shape of the nanocrystals on a significantly large amount of sample.

\section{Electrochemical characterization and electrocatalysis}

Catalyst nanoparticles supported on a substrate are extensively used in many industrial applications of catalytic processes. ${ }^{54}$ It has been proven that the efficient shape-controlled synthesis of nanoparticles may have strong impact in large-scale applications. ${ }^{55}$ However, the approaches used so far to obtain nanoparticles with controlled shapes invariably involve additives and capping 
agents ${ }^{40,56}$, which cover the surface active sites, deteriorating the catalytic performance 26,57 as they are surface poisons or modifiers of the catalytic activity. ${ }^{58}$

In the field of electro-catalysis, there is a strong need of nanoparticles free of contaminations and preferentially shaped, as many electrocatalytic reactions of key importance for energy storage and conversion and wastewater remediation are highly structure-sensitive reactions. The possibility to have preferentially oriented nanoparticles represents a major breakthrough for catalysis. ${ }^{3,24,59}$

It is well established that, for Pt surfaces, the voltammetric profile in $0.5 \mathrm{M} \mathrm{H}_{2} \mathrm{SO}_{4}$ represents a fingerprint of their particular surface structure. ${ }^{35}$ Fig. 5 (left panel) reports the characteristic voltammetric profiles of the different octahedral Pt nanocrystals. At first sight, the sharpness and the symmetry of the adsorption states clearly point out the good cleanliness of the surface. In addition, all the three profiles are very similar and show characteristic voltammetric features associated with the presence of a well-defined (111) preferential surface orientation. In particular, it is worth noting the presence of the symmetric contribution at $0.5 \mathrm{~V}$, a feature related to the anion adsorption on twodimensionally ordered $\{111\}$ surface domains. Additionally, the sharp peak at $0.12 \mathrm{~V}$ is associated to the presence of (110) surface sites, likely steps between $\{111\}$ domains, which would be necessarily present on the surface of these small nanocrystals. Finally, the small peak at about $0.26 \mathrm{~V}$ is attributed to the (100) surface sites, both at the edges and corners between the $\{111\}$ domains. It is worth noting that these voltammetric profiles are very similar to those observed with clean octahedral Pt nanocrystals prepared using other methodologies, that is, prepared in the presence of other capping agents (Fig. S12). However, in comparison with these previous findings, it is important to underline the absence of contributions between 0.35 and $0.37 \mathrm{~V}$, where the characteristic features of two-dimensional $\{100\}$ surface domains appear. This fact points out the high quality of the present samples (in term of (111) preferential surface structure). This voltammetric characterization, obtained from a large number of nanocrystals, further confirms the results from TEM and XRD analyses. Interestingly, the voltammograms of the octahedral Pt nanocrystals are very similar to that of Pt(554) single crystal surface (Fig. 5, right panel). This Pt(554) 
surface is a combination of (111) terraces with 9 atom-width separated by monoatomic (110) step sites. Additionally, as a comparison, the voltammetric profile of quasi-spherical (3-4 nm) Pt nanoparticles, prepared in presence of citrate using the methodology previously described (See SI for details about the preparation and characterization of this sample, Fig. S13), ${ }^{32}$ is also included in Fig. S15. As expected, the quasi-spherical Pt nanoparticles display a voltammetric profile characteristic of a polyoriented Pt surface in which it worth noting the absence of the signal at about $0.4-0.6 \mathrm{~V}$ related to the $\{111\}$ surface structure (Fig S15, right panel). To obtain quantitative information of the $\{111\}$ at the surface of the octahedral Pt nanocrystals, irreversible $\mathrm{Bi}$ adsorption experiments were performed as described in previous publications ${ }^{37}$, and tentatively characterized by STEM EDS (Figs. S16b-c). Briefly, the charge involved in the oxidation process, related to the presence of these irreversibly adsorbed adatoms, can be easily correlated with the percentage of $\{111\}$ surface domains by using the relationships deduced for series of well-defined stepped surfaces. Fig. S16a shows the electrochemical responses of the electrode after the irreversible adsorption of $\mathrm{Bi}$ at maximum coverage in comparison with the bare surface. The presence of $\mathrm{Bi}$ completely hinders/blocks the usual adsorption/desorption features of the nanocrystals, and only the characteristic surface redox process due to the adsorbed bismuth is observed at about $0.63 \mathrm{~V}$. This surface redox process is observed in all samples, although Pt NC18 display a much higher Bi redox charge, which already indicates a higher proportion of $\{111\}$ surface domains.

Table 1 summarizes the results for the three different sets of nanocrystals (see SI and Fig. S17 for details).

Table 1. Percentage of the $\{111\}$ ordered domains determined for the different sets of nanocrystals.

\begin{tabular}{|c|c|c|c|}
\hline Sample & Pt NC7 & Pt NC10 & Pt NC18 \\
\hline$\{111\}$ sites $(\%)$ & $\mathbf{3 9 . 2} \pm \mathbf{0 . 3}$ & $\mathbf{4 0 . 9} \pm \mathbf{0 . 3}$ & $\mathbf{6 9 . 3} \pm \mathbf{0 . 3}$ \\
\hline
\end{tabular}


The Pt NC18 shows an impressive value of about 70\%, which evidences the high quality of the sample in terms of (111) surface structure. Moreover, elemental mapping of Bi over the particles does not show clear localization of Bi over the particles in defined regions (Figs. S16b-c). However, the value of about $40 \%$ for the Pt NC7 is more relevant as it clearly indicates that the decrease in particle size from 10 to $7 \mathrm{~nm}$ does not imply a loss of (111) character, which is clearly important for practical applications.

For the 3-4 nm quasi-spherical Pt nanoparticles (Fig. S18), the characteristic features associated with the adsorption of Bi on $\{111\}$ domains are essentially missing due to the absence of $\{111\}$ terraces at the surface of the small Pt nanoparticles as previously demonstrated in Fig. S15, right panel. In this regard, it is worth mention that, due to the absence of well-defined surface domains in which Bi can be adsorbed, the surface of the small nanoparticles is not fully covered by the $\mathrm{Bi}$ atoms and, consequently, the so-called hydrogen region remains clearly visible. A similar finding was previously observed with 4-5 nm spherical Pt nanoparticles. ${ }^{35}$

The oxidation of formic acid on platinum surfaces has been the subject of innumerable contributions, not only because it is a two-electron-transfer model reaction, but also for its potential use in direct formic acid fuel cells (DFAFCs). ${ }^{60}$ It is widely accepted that the reaction proceeds through a dual path mechanism: the direct oxidation path to $\mathrm{CO}_{2}$ and a second pathway, which involves a dehydration step to yield water and adsorbed CO, a poisoning intermediate, further oxidized to $\mathrm{CO}_{2}$ at high overpotentials. In addition, it is well-established that both paths are structure-sensitive processes. It is well-known that the $\operatorname{Pt}(100)$ is the most active surface, but also the most sensitive to the CO poisoning. On the other hand, for $\operatorname{Pt}(111)$ surface the poisoning rate is significantly lower, a very important property for long operation times. ${ }^{23}$

It is also well-recognized that the dehydration step to yield CO requires an "ensemble" of Pt surface atoms. ${ }^{61}$ Consequently, by perturbing this required ensemble, the CO formation step can be inhibited, giving rise to an enhancement of the overall oxidation rate. This surface perturbation can be easily achieved with the use of adsorbed adatoms as surface modifiers. This strategy has been widely used with Pt single crystal electrodes. ${ }^{62-63}$ From these fundamental 
studies, it was reported that, on Pt(111), the adsorption of Bi enhanced about 40 times the activity of platinum surface for the direct oxidation of formic acid, whereas the poisoning effect due to spontaneous formation of $\mathrm{CO}$ was almost completely suppressed, even at a very low coverage. .2-63 $^{6}$

From a practical point of view, the use of single crystal surfaces is not reasonable, and nanomaterials are essential due to their much higher surface to volume ratio. Shape-controlled Pt nanocrystals fulfill these two requirements: high surface to volume ratio and well-defined surface structure. Previous contributions have studied the electrocatalytic properties of different shape-controlled $\mathrm{Pt}$ nanocrystals towards formic acid electro-oxidation. These studies evidenced the same structural electrocatalytic dependence, related to the presence of facets with (100) and (111) symmetry, as that observed with the model Pt surfaces. Additionally, to enhance the activity and/or to overcome the poisoning effect, the shaped Pt nanocrystals were also decorated with adatoms such as $\mathrm{Pd}{ }^{64}, \mathrm{Bi}, 65,46,47$ or $\mathrm{Sb} .{ }^{66}$ However, in these studies, the particle size of the samples (about $10 \mathrm{~nm}$ ) is still too large from a practical point of view. Decreasing the particle size from 9 to $2 \mathrm{~nm}$ resulted in enhanced activities due to the "catalytic ensemble effect", i.e. the lack of the Pt site ensemble requirement for the CO poisoning process. ${ }^{67}$ Consequently, the possibility of studying the formic acid electro-oxidation on Bi decorated, (111) preferentially oriented, $7 \mathrm{~nm}$ octahedral Pt nanocrystals would strongly contribute to the next generation of advanced electrocatalysts for energy conversion applications.

Fig. S19 shows the voltammetric responses of the different octahedral Pt nanocrystals in a $0.5 \mathrm{M} \mathrm{H}_{2} \mathrm{SO}_{4}+0.5 \mathrm{M} \mathrm{HCOOH}$ solution. As comparison, the response of the quasi-spherical (3-4 nm) Pt nanoparticles is also included. The upper potential limit has been restricted to $0.9 \mathrm{~V}$ in all samples, to avoid surface structure perturbations and some electrochemical dissolution in this high potential range. As expected, their electrocatalytic response is rather similar, due to their similar preferential surface structure. Thus, in the positive going scan, CO from dehydration of formic acid is formed at low potentials and importantly hinders the direct oxidation path. In this positive going scan, the activity of the small Pt nanoparticles is slightly better because of their smaller particle size. ${ }^{67}$ Once the $\mathrm{CO}$ poison is oxidized between $0.7-0.9 \mathrm{~V}$, in the negative scan, between 
0.9 and $0.5 \mathrm{~V}$, the electrode is CO free and good oxidation currents are obtained. Finally, from $0.55 \mathrm{~V}$, current again decreases due to CO re-poisoning of the surface. However, it is also worth noting that the $18 \mathrm{~nm}$ octahedral Pt nanocrystals display a distinct behavior at high potential values in both the negative and positive going sweep. This is due to their higher (111) character, as deduced from previous contribution with different shape-controlled Pt nanocrystals. ${ }^{68}$

Fig. S20 reports the voltammograms corresponding to the formic acid electrooxidation obtained with the different Bi-modified octahedral Pt nanocrystals also including the response obtained with the Bi-modified quasi-spherical $\mathrm{Pt}$ nanoparticles as well as that obtained with two types of Pd nanoparticles (2-3 $\mathrm{nm}$ spherical Pd nanoparticles prepared in the presence of citrate [See SI for details about the preparation and characterization of this sample, Fig. S14] and a commercial Pd black (Alfa Aesar)) which represent the state-of-the-art for formic acid electrooxidation. From the graphs it is clear that a huge increase in current is obtained with the Bi decorated samples. In addition, as it is also wellknown for the Pd samples, the hysteresis between the positive and negativegoing sweep is remarkably small, thus suggesting that the dehydration rate is slower and negligible amounts of $\mathrm{CO}$ are accumulated at the surface of the Bimodified nanocrystals during the positive going scan. However, it is worth noting that the activity of the $\mathrm{Bi}$ decorated quasi-spherical $\mathrm{Pt}$ nanoparticles is significantly worse that that found with the octahedral samples, thus evidencing the important role played by the surface structure of the nanocrystals.

To analyze the response of the octahedral Pt nanocrystals under more practical conditions, chronoamperometric measurements were recorded at different potentials (0.3, 0.4 and $0.5 \mathrm{~V}$ vs RHE) for 25 minutes. Fig. S21 shows the results obtained and Fig. 6 summarizes the findings. As expected, and independently of the applied potential, the currents obtained with the Bi-modified samples are much higher than those observed with the bare ones. However, the most interesting finding is the performance of $7 \mathrm{~nm}$ Bi-decorated octahedral nanocrystals that display a clear enhancement in comparison with the 10 and 18 
$\mathrm{nm}$ ones. This is particularly important because these results are referred to specific activities (SA), i.e. activity normalized to the electroactive surface area and, consequently, expressed in terms of $\mathrm{mA} \mathrm{cm}^{-2}$ (the electroactive surface area of the three samples, estimated as described in the Methods section, is similar and equal to about $0.185 \pm 0.03 \mathrm{~cm}^{2}$ ).

On the other hand, it is worth noting that a decrease in particle size, from 18 to 7 $\mathrm{nm}$, directly implies an increase in the surface area to volume ratio from approximately 0.4 to 1.0 . In this way, for a similar total surface area $0.185 \pm$ $0.03 \mathrm{~cm}^{2}$ in the present case), the total volume and, consequently the required mass of $\mathrm{Pt}$, is remarkably reduced by a factor of about 2.5 , thus effectively reducing the cost of the electrocatalysts.

\section{Conclusion}

We have reported a "green" synthetic procedure of octahedral Pt nanocrystals. The synergy between sodium citrate, ascorbic acid, and fine control of the reduction rate is the key point governing the synthesis. The method permits fine tuning of the size of the nanomaterial and can be easily scaled-up. Nanocrystals with size as low as $7 \mathrm{~nm}$ with highly developed $\{111\}$ facets have been obtained. In the electro-oxidation of formic acid, the $7 \mathrm{~nm}$ octahedral nanocrystals fully decorated with bismuth displayed an enhanced performance in terms of both specific and mass activity than those obtained with the 10 and $18 \mathrm{~nm}$ ones. These findings may remarkably impact their possible application in fuel cell technology, where the high cost of the electrocatalysts is one of the critical aspects. For this purpose, the production of 3-5 nm octahedral Pt nanocrystals with highly developed and clean $\{111\}$ facets still represents a major challenge.

\section{Author Contributions}

MM conceived the synthetic procedure for octahedral nanocrystal syntheses. MM, DP and PD perfomed the optimization and the scale-up of the synthetic process. RB and DD performed TEM experiments and analysis. CG and TS 
performed XRD measurements. JSG, VM and JMF conceived the electrochemical application of the nanomaterials. JSG performed the electrochemical characterization and the formic acid electrooxidation experiments. MM, JSG and PPP conceived the project and analyzed data. All the authors contributed to the elaboration of the manuscript.

\section{Acknowledgments}

We are grateful to Valentina Mastronardi, Vito Maggi, Lucia Pavoni, Costanza Fabbracci and Diego Bomprezzi for the help in some experiments. We also thank Elisa De Luca, Enrico Marcantoni and Fabian Meemken for helpful discussions. JMF and VM acknowledge financial support from MINECO (projects CTQ2016-76221-P and CTQ2016-76231-C2-2-R (AEI/FEDER, UE)). JSG acknowledges financial support from VITC (Vicerrectorado de Investigación y Transferencia de Conocimiento) of the University of Alicante (UATALENTO1602).

Competing financial interests: The authors declare no competing financial interests.

Supporting Information: TEM images, STEM images, EDS analysis, synthetic protocols, XRD analysis, voltammograms, formic acid electrooxidation, chronoamperometric measurements.

\section{References}

(1) Xia, Y.; Yang, X. Toward Cost-Effective and Sustainable Use of Precious Metals in Heterogeneous Catalysts. Acc. Chem. Res. 2017, 50 (3), 450-454, DOI: 10.1021/acs.accounts.6b00469.

(2) Helmlinger, J.; Sengstock, C.; Gro; Mayer, C.; Schildhauer, T. A.; Koller, M.; Epple, M. Silver nanoparticles with different size and shape: equal cytotoxicity, but different antibacterial effects. RSC Adv. 2016, 6 (22), 18490-18501, DOI: 10.1039/C5RA27836H.

(3) Koper, M. T. M. Structure sensitivity and nanoscale effects in electrocatalysis. Nanoscale 2011, 3 (5), 2054-2073, DOI: 10.1039/C0NR00857E.

(4) Liz-Marzán, L. M.; Grzelczak, M. Growing anisotropic crystals at the nanoscale. Science 2017, 356 (6343), 1120-1121, DOI: 10.1126/science.aam8774.

(5) Ruditskiy, A.; Xia, Y. The Science and Art of Carving Metal Nanocrystals. ACS Nano 2017, 11 (1), 23-27, DOI: 10.1021/acsnano.6b08556.

(6) Puntes, V. F.; Krishnan, K. M.; Alivisatos, A. P. Colloidal Nanocrystal Shape and Size Control: The Case of Cobalt. Science 2001, 291 (5511), 2115-2117, DOI: 10.1126/science.1058495.

(7) Herricks, T.; Chen, J.; Xia, Y. Polyol Synthesis of Platinum Nanoparticles: Control of Morphology with Sodium Nitrate. Nano Lett. 2004, 4 (12), 2367-2371, DOI: $10.1021 /$ nl048570a. 
(8) Gole, A.; Murphy, C. J. Seed-Mediated Synthesis of Gold Nanorods: Role of the Size and Nature of the Seed. Chem. Mater. 2004, 16 (19), 3633-3640, DOI: $10.1021 / \mathrm{cm} 0492336$.

(9) Castelli, A.; Striolo, A.; Roig, A.; Murphy, C.; Reguera, J.; Liz-Marzan, L.; Mueller, A.; Critchley, K.; Zhou, Y.; Brust, M.; Thill, A.; Scarabelli, L.; Tadiello, L.; Konig, T. A. F.; Reiser, B.; Lopez-Quintela, M. A.; Buzza, M.; Deak, A.; Kuttner, C.; Gonzalez Solveyra, E.; Pasquato, L.; Portehault, D.; Mattoussi, H.; Kotov, N. A.; Kumacheva, E.; Heatley, K.; Bergueiro, J.; Gonzalez, G.; Tong, W.; Tahir, M. N.; Abecassis, B.; Rojas-Carrillo, O.; Xia, Y.; Mayer, M.; Peddis, D. Anisotropic nanoparticles: general discussion. Faraday Discuss. 2016, 191 (0), 229-254, DOI: 10.1039/C6FD90049F. (10) Yanson, A. I.; Rodriguez, P.; Garcia-Araez, N.; Mom, R. V.; Tichelaar, F. D.; Koper, M. T. M. Cathodic Corrosion: A Quick, Clean, and Versatile Method for the Synthesis of Metallic Nanoparticles. Angew. Chem., Int. Ed. 2011, 50 (28), 63466350, DOI: 10.1002/anie.201100471.

(11) Yanson, A. I.; Antonov, P. V.; Yanson, Y. I.; Koper, M. T. M. Controlling the size of platinum nanoparticles prepared by cathodic corrosion. Electrochim. Acta 2013, $110 \quad$ (Supplement $\quad$ C), 796-800, https://doi.org/10.1016/j.electacta.2013.03.121.

(12) Miyabayashi, K.; Nakamura, S.; Miyake, M. Synthesis of Small Platinum Cube with Less Than $3 \mathrm{~nm}$ by the Control of Growth Kinetics. Cryst. Growth Des. 2011, 11 (10), 4292-4295, DOI: 10.1021/cg200937u.

(13) Leong, G. J.; Schulze, M. C.; Strand, M. B.; Maloney, D.; Frisco, S. L.; Dinh, H. N.; Pivovar, B.; Richards, R. M. Shape-directed platinum nanoparticle synthesis: nanoscale design of novel catalysts. Appl. Organomet. Chem. 2014, 28 (1), 1-17, DOI: $10.1002 /$ aoc.3048.

(14) Yang, T.-H.; Gilroy, K. D.; Xia, Y. Reduction rate as a quantitative knob for achieving deterministic synthesis of colloidal metal nanocrystals. Chem. Sci. 2017, 8 (10), 6730-6749, DOI: 10.1039/C7SC02833D.

(15) Zhang, L.; Roling, L. T.; Wang, X.; Vara, M.; Chi, M.; Liu, J.; Choi, S.-I.; Park, J.; Herron, J. A.; Xie, Z.; Mavrikakis, M.; Xia, Y. Platinum-based nanocages with subnanometer-thick walls and well-defined, controllable facets. Science 2015, 349 (6246), 412-416, DOI: 10.1126/science.aab0801.

(16) Wang, X.; Choi, S.-I.; Roling, L. T.; Luo, M.; Ma, C.; Zhang, L.; Chi, M.; Liu, J.; Xie, Z.; Herron, J. A.; Mavrikakis, M.; Xia, Y. Palladium-platinum core-shell icosahedra with substantially enhanced activity and durability towards oxygen reduction. 2015, 6, 7594, DOI: 10.1038/ncomms8594

https://www.nature.com/articles/ncomms8594\#supplementary-information.

(17) Jiang, B.; Li, C.; Malgras, V.; Imura, M.; Tominaka, S.; Yamauchi, Y. Mesoporous $\mathrm{Pt}$ nanospheres with designed pore surface as highly active electrocatalyst. Chem. Sci. 2016, 7 (2), 1575-1581, DOI: 10.1039/C5SC03779D.

(18) Ataee-Esfahani, H.; Wang, L.; Nemoto, Y.; Yamauchi, Y. Synthesis of Bimetallic Au@Pt Nanoparticles with Au Core and Nanostructured Pt Shell toward Highly Active Electrocatalysts. Chem. Mater. 2010, 22 (23), 6310-6318, DOI: $10.1021 / \mathrm{cm} 102074 \mathrm{w}$.

(19) Wang, L.; Yamauchi, Y. Strategic Synthesis of Trimetallic Au@Pd@Pt Core-Shell Nanoparticles from Poly(vinylpyrrolidone)-Based Aqueous Solution toward Highly Active Electrocatalysts. Chem. Mater. 2011, 23 (9), 2457-2465, DOI: $10.1021 / \mathrm{cm} 200382 \mathrm{~s}$. 
(20) Li, C.; Sato, T.; Yamauchi, Y. Electrochemical Synthesis of One-Dimensional Mesoporous Pt Nanorods Using the Assembly of Surfactant Micelles in Confined Space. Angew. Chem., Int. Ed. 2013, 52 (31), 8050-8053, DOI: doi:10.1002/anie.201303035.

(21) Wang, H.; Jeong, H. Y.; Imura, M.; Wang, L.; Radhakrishnan, L.; Fujita, N.; Castle, T.; Terasaki, O.; Yamauchi, Y. Shape- and Size-Controlled Synthesis in Hard Templates: Sophisticated Chemical Reduction for Mesoporous Monocrystalline Platinum Nanoparticles. J. Am. Chem. Soc. 2011, 133 (37), 14526-14529, DOI: 10.1021/ja2058617.

(22) Montiel, M. A.; Vidal-Iglesias, F. J.; Montiel, V.; Solla-Gullón, J. Electrocatalysis on shape-controlled metal nanoparticles: Progress in surface cleaning methodologies. Curr. Opin. Electrochem. 2017, 1 (1), 34-39, DOI: https://doi.org/10.1016/j.coelec.2016.12.007.

(23) Herrero, E.; Feliu, J. M. Handbook of Fuel Cells. Fundamentals and Application, 2003; Vol. 2.

(24) Vidal-Iglesias, F. J.; Solla-Gullón, J.; Feliu, J. M. Recent Advances in the Use of Shape-Controlled Metal Nanoparticles in Electrocatalysis. In Nanomaterials for Fuel Cell Catalysis; Ozoemena, K. I.; Chen, S., Eds.; Springer International Publishing: Cham, 2016; pp 31-92.

(25) Miyazaki, A.; Balint, I.; Nakano, Y. Morphology Control of Platinum Nanoparticles and their Catalytic Properties. J. Nanopart. Res. 2003, 5 (1-2), 6980, DOI: $10.1023 /$ A:1024451600613.

(26) Kuhn, J. N.; Tsung, C.-K.; Huang, W.; Somorjai, G. A. Effect of organic capping layers over monodisperse platinum nanoparticles upon activity for ethylene hydrogenation and carbon monoxide oxidation. J. Catal. 2009, 265 (2), 209-215, DOI: http://dx.doi.org/10.1016/j.jcat.2009.05.001.

(27) Vidal-Iglesias, F. J.; Solla-Gullón, J.; Herrero, E.; Montiel, V.; Aldaz, A.; Feliu, J. $\mathrm{M}$. Evaluating the ozone cleaning treatment in shape-controlled Pt nanoparticles: Evidences of atomic surface disordering. Electrochem. Commun. 2011, 13 (5), 502-505, DOI: https://doi.org/10.1016/j.elecom.2011.02.033.

(28) Kinoshita, K. Particle Size Effects for Oxygen Reduction on Highly Dispersed Platinum in Acid Electrolytes. J. Electrochem. Soc. 1990, 137 (3), 845-848, DOI: 10.1149/1.2086566.

(29) Gammer, C.; Mangler, C.; Rentenberger, C.; Karnthaler, H. P. Quantitative local profile analysis of nanomaterials by electron diffraction. Scr. Mater. 2010, 63 (3), 312-315, DOI: https://doi.org/10.1016/j.scriptamat.2010.04.019.

(30) Schneider, C. A.; Rasband, W. S.; Eliceiri, K. W. NIH Image to ImageJ: 25 years of image analysis. Nat. Methods 2012, 9, 671, DOI: 10.1038/nmeth.2089.

(31) Momma, K.; Izumi, F. VESTA 3 for three-dimensional visualization of crystal, volumetric and morphology data. J. Appl. Crystallogr. 2011, 44 (6), 1272-1276, DOI: doi:10.1107/S0021889811038970.

(32) López-Cudero, A.; Solla-Gullón, J.; Herrero, E.; Aldaz, A.; Feliu, J. M. CO electrooxidation on carbon supported platinum nanoparticles: Effect of aggregation. J. Electroanal. Chem. 2010, 644 (2), 117-126, DOI: https://doi.org/10.1016/j.jelechem.2009.06.016.

(33) Chen, Q.-S.; Solla-Gullón, J.; Sun, S.-G.; Feliu, J. M. The potential of zero total charge of Pt nanoparticles and polycrystalline electrodes with different surface structure: The role of anion adsorption in fundamental electrocatalysis. 
Electrochim. Acta 2010, 55 (27), 7982-7994, DOI: https://doi.org/10.1016/j.electacta.2010.03.050.

(34) Rodríguez, P.; Solla-Gullón, J.; Vidal-Iglesias, F. J.; Herrero, E.; Aldaz, A.; Feliu, J. M. Determination of (111) Ordered Domains on Platinum Electrodes by Irreversible Adsorption of Bismuth. Anal. Chem. 2005, 77 (16), 5317-5323, DOI: 10.1021/ac050347q.

(35) Solla-Gullon, J.; Rodriguez, P.; Herrero, E.; Aldaz, A.; Feliu, J. M. Surface characterization of platinum electrodes. Phys. Chem. Chem. Phys. 2008, 10 (10), 1359-1373, DOI: 10.1039/B709809J.

(36) Liz-Marzán, L. M. Increasing Complexity while Maintaining a High Degree of Symmetry in Nanocrystal Growth. Angew. Chem., Int. Ed. 2015, 54 (13), 38603861, DOI: 10.1002/anie.201411800.

(37) Gisbert-González, J. M.; Feliu, J. M.; Ferre-Vilaplana, A.; Herrero, E. Why Citrate Shapes Tetrahedral and Octahedral Colloidal Platinum Nanoparticles in Water. J. Phys. Chem. C 2018, 122 (33), 19004-19014, DOI: 10.1021/acs.jpcc.8b05195.

(38) Yang, T.-H.; Peng, H.-C.; Zhou, S.; Lee, C.-T.; Bao, S.; Lee, Y.-H.; Wu, J.-M.; Xia, Y. Toward a Quantitative Understanding of the Reduction Pathways of a Salt Precursor in the Synthesis of Metal Nanocrystals. Nano Lett. 2017, 17 (1), 334340, DOI: 10.1021/acs.nanolett.6b04151.

(39) Yin, J.; Wang, J.; Li, M.; Jin, C.; Zhang, T. Iodine Ions Mediated Formation of Monomorphic Single-Crystalline Platinum Nanoflowers. Chem. Mater. 2012, 24 (14), 2645-2654, DOI: 10.1021/cm300056h.

(40) Ahmadi, T. S.; Wang, Z. L.; Green, T. C.; Henglein, A.; El-Sayed, M. A. ShapeControlled Synthesis of Colloidal Platinum Nanoparticles. Science 1996, 272 (5270), 1924-1925, DOI: 10.1126/science.272.5270.1924.

(41) Tsung, C.-K.; Kuhn, J. N.; Huang, W.; Aliaga, C.; Hung, L.-I.; Somorjai, G. A.; Yang, P. Sub-10 nm Platinum Nanocrystals with Size and Shape Control: Catalytic Study for Ethylene and Pyrrole Hydrogenation. J. Am. Chem. Soc. 2009, 131 (16), 5816-5822, DOI: 10.1021/ja809936n.

(42) Chiu, C.-Y.; Li, Y.; Ruan, L.; Ye, X.; Murray, C. B.; Huang, Y. Platinum nanocrystals selectively shaped using facet-specific peptide sequences. Nat Chem 2011, 3 (5), 393-399, http://www.nature.com/nchem/journal/v3/n5/abs/nchem.1025.html\#supple mentary-information.

(43) Lim, S. I.; Ojea-Jiménez, I.; Varon, M.; Casals, E.; Arbiol, J.; Puntes, V. Synthesis of Platinum Cubes, Polypods, Cuboctahedrons, and Raspberries Assisted by Cobalt Nanocrystals. Nano Lett. 2010, 10 (3), 964-973, DOI: $10.1021 / \mathrm{nl} 100032 \mathrm{c}$.

(44) Vidal-Iglesias, F. J.; Arán-Ais, R. M.; Solla-Gullón, J.; Herrero, E.; Feliu, J. M. Electrochemical Characterization of Shape-Controlled $\mathrm{Pt}$ Nanoparticles in Different Supporting Electrolytes. ACS Catal. 2012, 2 (5), 901-910, DOI: $10.1021 / \operatorname{cs} 200681 x$.

(45) Song, H.; Kim, F.; Connor, S.; Somorjai, G. A.; Yang, P. Pt Nanocrystals: Shape Control and Langmuir-Blodgett Monolayer Formation. J. Phys. Chem. B 2005, 109 (1), 188-193, DOI: 10.1021/jp0464775.

(46) Mostafa, S.; Behafarid, F.; Croy, J. R.; Ono, L. K.; Li, L.; Yang, J. C.; Frenkel, A. I.; Cuenya, B. R. Shape-Dependent Catalytic Properties of Pt Nanoparticles. J. Am. Chem. Soc. 2010, 132 (44), 15714-15719, DOI: 10.1021/ja106679z. 
(47) Kilin, D. S.; Prezhdo, O. V.; Xia, Y. Shape-controlled synthesis of silver nanoparticles: $\mathrm{Ab}$ initio study of preferential surface coordination with citric acid. Chem. Phys. Lett. 2008, 458 (1), 113-116, DOI: https://doi.org/10.1016/j.cplett.2008.04.046.

(48) Adil, S. F.; Assal, M. E.; Khan, M.; Al-Warthan, A.; Siddiqui, M. R. H.; LizMarzan, L. M. Biogenic synthesis of metallic nanoparticles and prospects toward green chemistry. Dalton Trans. 2015, 44 (21), 9709-9717, DOI: 10.1039/C4DT03222E.

(49) Palosz, B.; Grzanka, E.; Gierlotka, S.; Stel'makh, S.; Pielaszek, R.; Bismayer, U.; Neuefeind, J.; Weber, H. P.; Proffen, T.; Von Dreele, R.; Palosz, W., Analysis of short and long range atomic order in nanocrystalline diamonds with application of powder diffractometry. In Zeitschrift für Kristallographie - Crystalline Materials, 2002; Vol. 217, p 497.

(50) Kaszkur, Z. Nanopowder diffraction analysis beyond the Bragg law applied to palladium. J. Appl. Crystallogr. 2000, 33 (1), 87-94, DOI: doi:10.1107/S002188989901290X.

(51) Cervellino, A.; Giannini, C.; Guagliardi, A. Determination of nanoparticle structure type, size and strain distribution from X-ray data for monatomic f.c.c.derived non-crystallographic nanoclusters. J. Appl. Crystallogr. 2003, 36 (5), 1148-1158, DOI: doi:10.1107/S0021889803013542.

(52) Cervellino, A.; Giannini, C.; Guagliardi, A. DEBUSSY: a Debye user system for nanocrystalline materials. J. Appl. Crystallogr. 2010, 43 (6), 1543-1547, DOI: doi:10.1107/S0021889810041889.

(53) Dorfs, D.; Krahne, R.; Falqui, A.; Manna, L.; Giannini, C.; Zanchet, D. 1.08 Quantum Dots: Synthesis and Characterization A2 - Andrews, David L. In Comprehensive Nanoscience and Technology; Scholes, G. D.; Wiederrecht, G. P., Eds.; Academic Press: Amsterdam, 2011; pp 219-270.

(54) Raimondi, F.; Scherer, G. G.; Kötz, R.; Wokaun, A. Nanoparticles in Energy Technology: Examples from Electrochemistry and Catalysis. Angew. Chem., Int. Ed. 2005, 44 (15), 2190-2209, DOI: 10.1002/anie.200460466.

(55) Li, Y.; Somorjai, G. A. Nanoscale Advances in Catalysis and Energy Applications. Nano Lett. 2010, 10 (7), 2289-2295, DOI: 10.1021/nl101807g.

(56) Yang, J.; Sargent, E.; Kelley, S.; Ying, J. Y. A general phase-transfer protocol for metal ions and its application in nanocrystal synthesis. Nat. Mater. 2009, 8 (8), 683-689, DOI: http://www.nature.com/nmat/journal/v8/n8/suppinfo/nmat2490_S1.html.

(57) Xia, Y.; Xiong, Y.; Lim, B.; Skrabalak, S. E. Shape-Controlled Synthesis of Metal Nanocrystals: Simple Chemistry Meets Complex Physics? Angew. Chem., Int. Ed. 2009, 48 (1), 60-103, DOI: 10.1002/anie.200802248.

(58) Kim, C.; Lee, H. Change in the catalytic reactivity of Pt nanocubes in the presence of different surface-capping agents. Catal. Commun. 2009, 10 (9), 13051309, DOI: http://dx.doi.org/10.1016/j.catcom.2009.02.013.

(59) Solla-Gullon, J.; Vidal-Iglesias, F. J.; Feliu, J. M. Shape dependent electrocatalysis. Annual Reports Section "C" (Physical Chemistry) 2011, 107 (0), 263-297, DOI: 10.1039/C1PC90010B.

(60) Rice, C.; Ha, S.; Masel, R. I.; Waszczuk, P.; Wieckowski, A.; Barnard, T. Direct formic acid fuel cells. J. Power Sources 2002, 111 (1), 83-89, DOI: https://doi.org/10.1016/S0378-7753(02)00271-9. 
(61) Leiva, E.; Iwasita, T.; Herrero, E.; Feliu, J. M. Effect of Adatoms in the Electrocatalysis of HCOOH Oxidation. A Theoretical Model. Langmuir 1997, 13 (23), 6287-6293, DOI: 10.1021/la970535e.

(62) Clavilier, J.; Fernandez-Vega, A.; Feliu, J. M.; Aldaz, A. Heterogeneous electrocatalysis on well defined platinum surfaces modified by controlled amounts of irreversibly adsorbed adatoms: Part I. Formic acid oxidation on the Pt (111)-Bi system. J.Electroanal. Chem. Interfacial Electrochem. 1989, 258 (1), 89-100, DOI: https://doi.org/10.1016/0022-0728(89)85164-2.

(63) Herrero, E.; Fernández-Vega, A.; Feliu, J. M.; Aldaz, A. Poison formation reaction from formic acid and methanol on $\mathrm{Pt}(111)$ electrodes modified by irreversibly adsorbed Bi and As. J. Electroanal. Chem. 1993, 350 (1), 73-88, DOI: https://doi.org/10.1016/0022-0728(93)80197-P.

(64) Vidal-Iglesias, F. J.; Solla-Gullón, J.; Herrero, E.; Aldaz, A.; Feliu, J. M. Pd Adatom Decorated (100) Preferentially Oriented Pt Nanoparticles for Formic Acid Electrooxidation. Angew. Chem., Int. Ed. 2010, 49 (39), 6998-7001, DOI: 10.1002/anie.201002501.

(65) Lopez-Cudero, A.; Vidal-Iglesias, F. J.; Solla-Gullon, J.; Herrero, E.; Aldaz, A.; Feliu, J. M. Formic acid electrooxidation on Bi-modified polyoriented and preferential (111) Pt nanoparticles. Phys. Chem. Chem. Phys. 2009, 11 (2), 416424, DOI: 10.1039/B814072C.

(66) Vidal-Iglesias, F. J.; López-Cudero, A.; Solla-Gullón, J.; Feliu, J. M. Towards More Active and Stable Electrocatalysts for Formic Acid Electrooxidation: Antimony-Decorated Octahedral Platinum Nanoparticles. Angew. Chem., Int. Ed. 2013, 52 (3), 964-967, DOI: 10.1002/anie.201207517.

(67) Park, S.; Xie, Y.; Weaver, M. J. Electrocatalytic Pathways on CarbonSupported Platinum Nanoparticles: Comparison of Particle-Size-Dependent Rates of Methanol, Formic Acid, and Formaldehyde Electrooxidation. Langmuir 2002, 18 (15), 5792-5798, DOI: 10.1021/la0200459.

(68) Solla-Gullon, J.; Vidal-Iglesias, F. J.; Lopez-Cudero, A.; Garnier, E.; Feliu, J. M.; Aldaz, A. Shape-dependent electrocatalysis: methanol and formic acid electrooxidation on preferentially oriented Pt nanoparticles. Phys. Chem. Chem. Phys. 2008, 10 (25), 3689-3698, DOI: 10.1039/B802703J. 

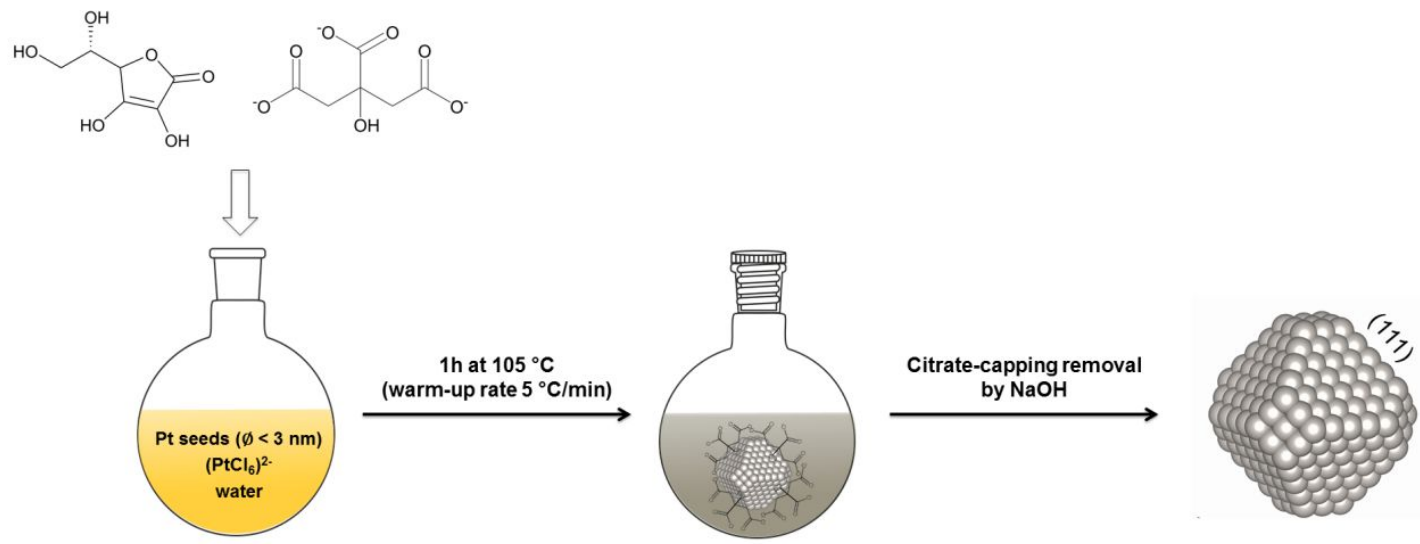

Figure 1. Scheme illustrating the synthetic method. 

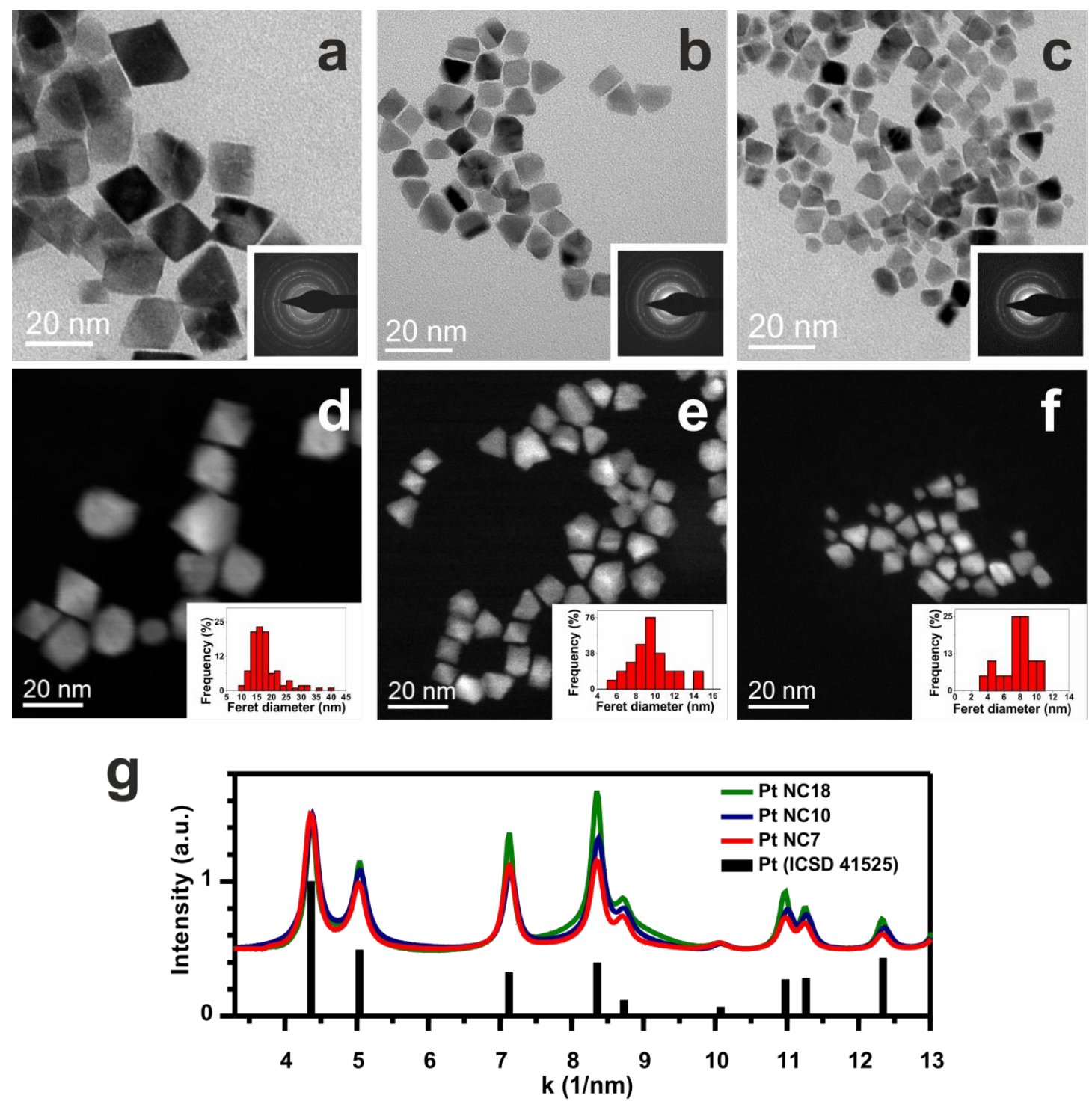

Figure 2. TEM investigation of Pt nanocrystals with average size (a,d) $18 \pm 2 \mathrm{~nm}$ (Pt NC18), (b,e) 10 \pm 2 nm (Pt NC10) and (c,f) 7 \pm 1 nm (Pt NC7): (a-c) BF-TEM and SAED patterns (in the insets) and (d-e) HAADF-STEM images and histograms of size distribution (in the insets). (g) Azimuthally integrated SAED patterns for the Pt NC18 (green), Pt NC10 (blue) and Pt NC7 (red), compared with a powder XRD pattern of a database Pt structure (black). 

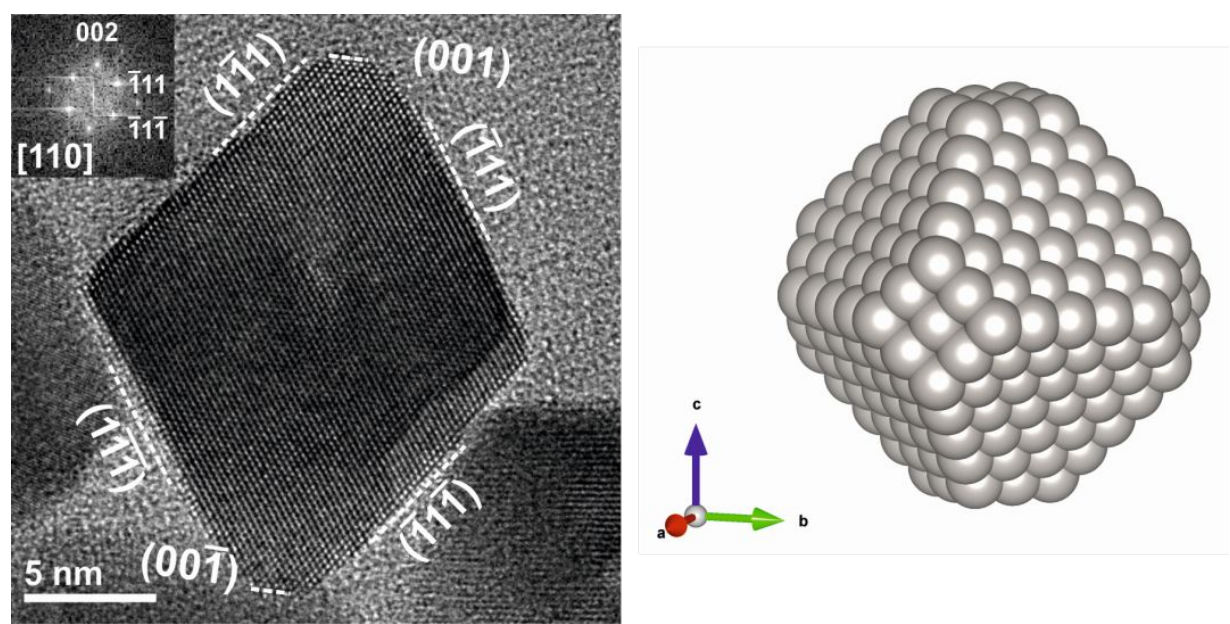

Figure 3. (Left) HRTEM image of a Pt single crystal (sample Pt NC18), exhibiting truncated octahedral shape, and (right) schematic model of a truncated octahedral Pt nanocrystal, obtained using VESTA. ${ }^{31}$ 

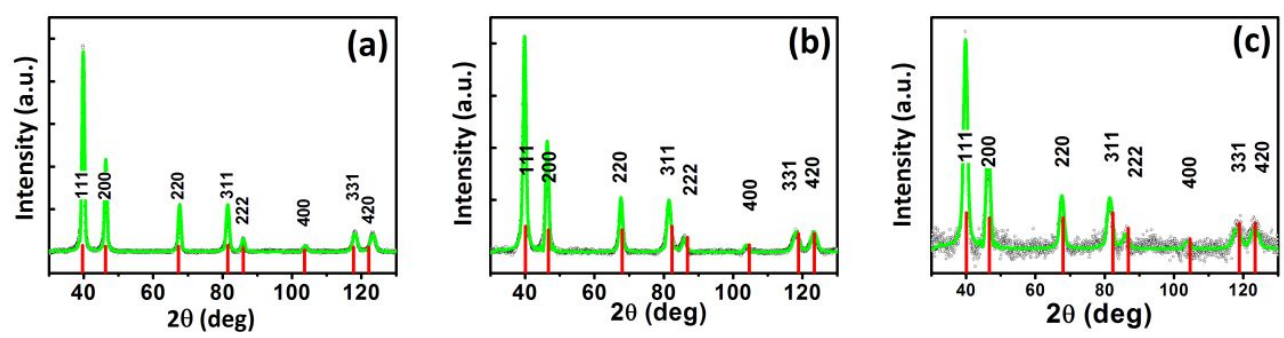

Figure 4. XRD data (experimental curve in black; theoretical curve in green) of Pt NC18 (a), Pt NC10 (b) and Pt NC7 (c) with crystalline dimension of $18 \pm 2 \mathrm{~nm}$, $8 \pm 2 \mathrm{~nm}$ and $6 \pm 2 \mathrm{~nm}$, respectively. 

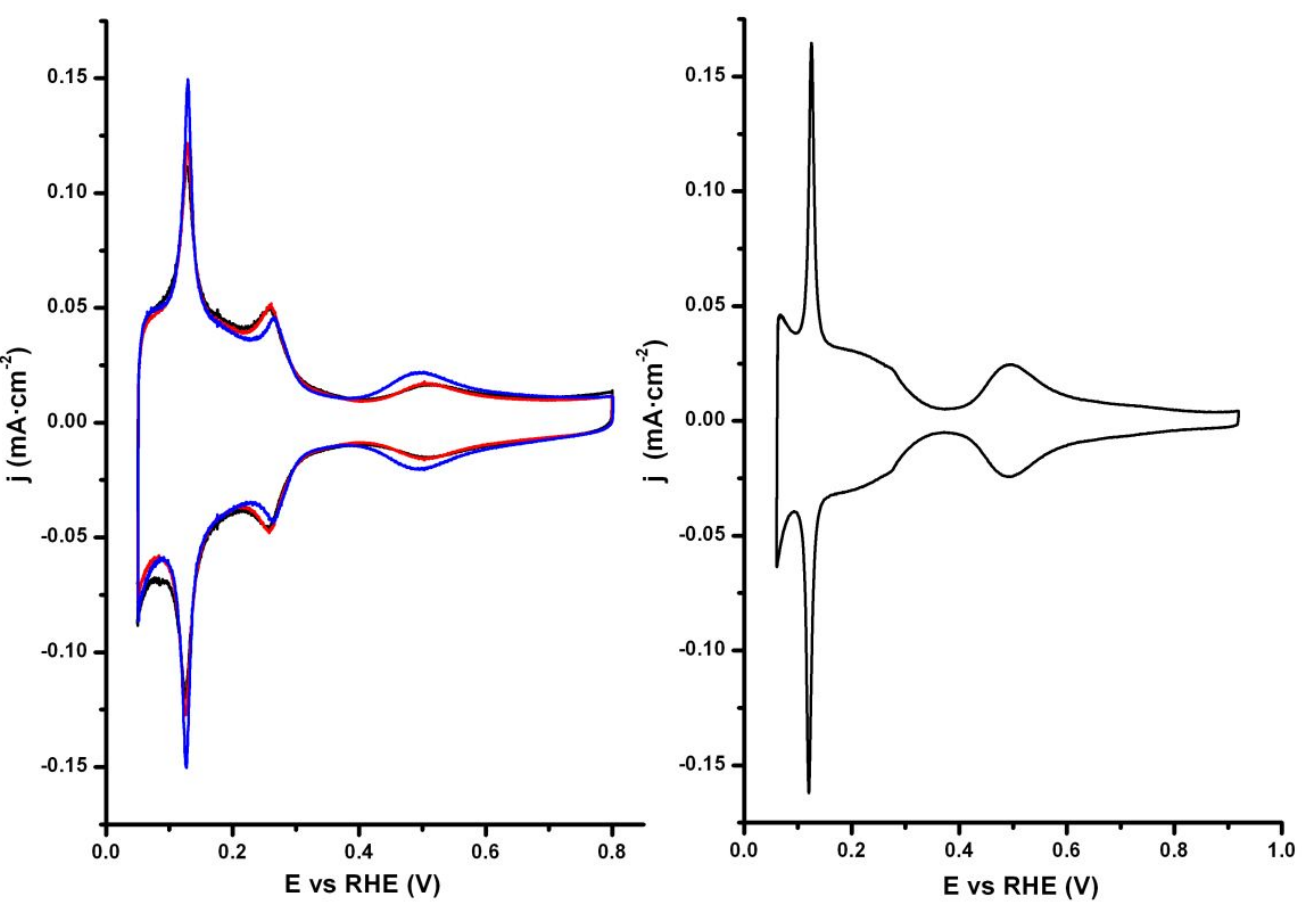

Figure 5. (Left) Cyclic voltammograms corresponding to Pt NC18 (blue), Pt NC 10 (red) and Pt NC7 (black). (Right) Cyclic voltammogram of a Pt(554) single crystal electrode. Test solution: $0.5 \mathrm{M} \mathrm{H}_{2} \mathrm{SO}_{4}$, sweep rate $50 \mathrm{mV} \mathrm{s}^{-1}$. 

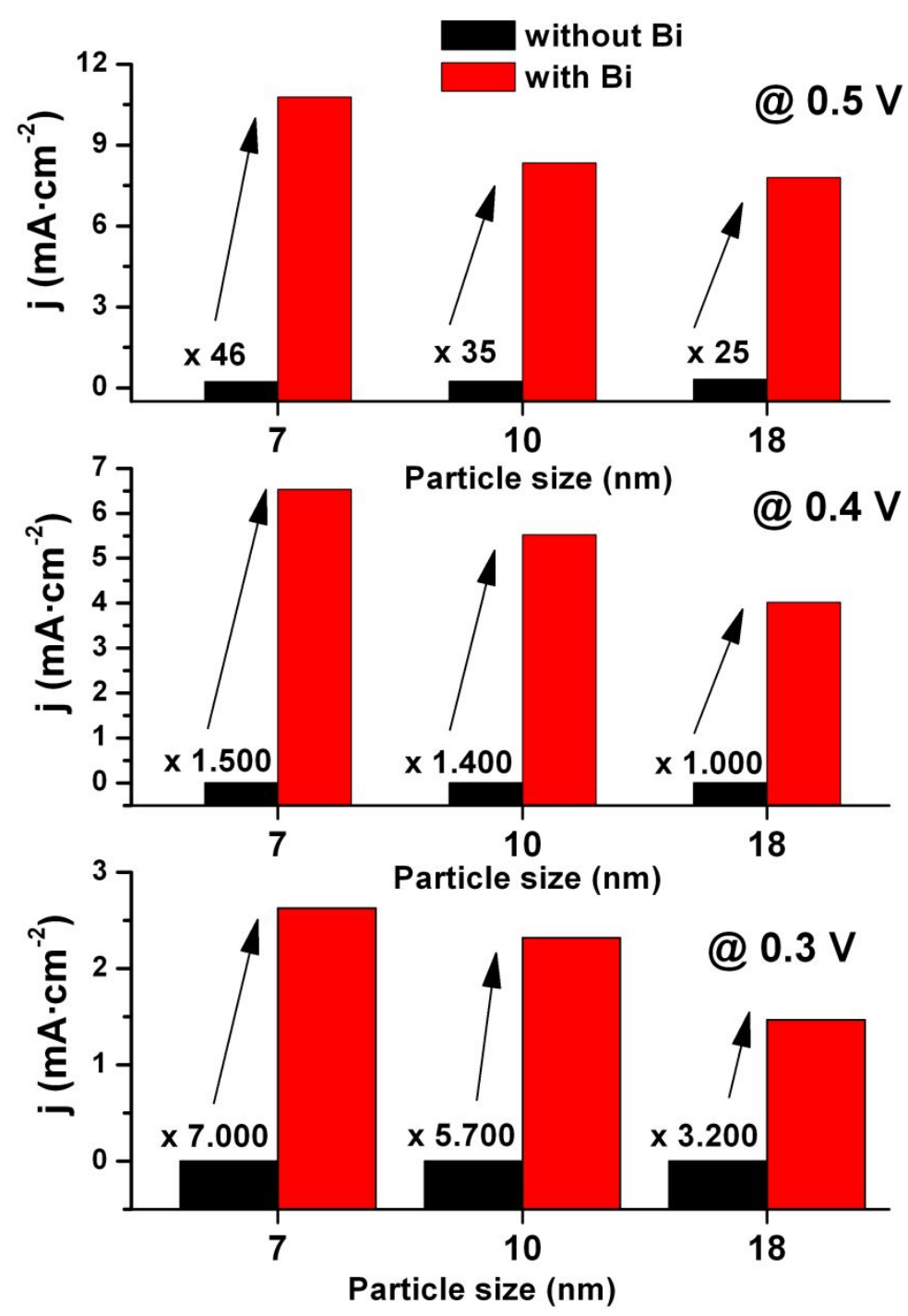

Figure 6. Formic acid current densities and enhancement factor obtained after $25 \mathrm{~min}$ at different applied potentials on Bi-modified (red columns) and bare (black columns) octahedral Pt nanocrystals. Test solution: $0.5 \mathrm{M} \mathrm{H}_{2} \mathrm{SO}_{4}+0.5 \mathrm{M}$ $\mathrm{HCOOH}$. 

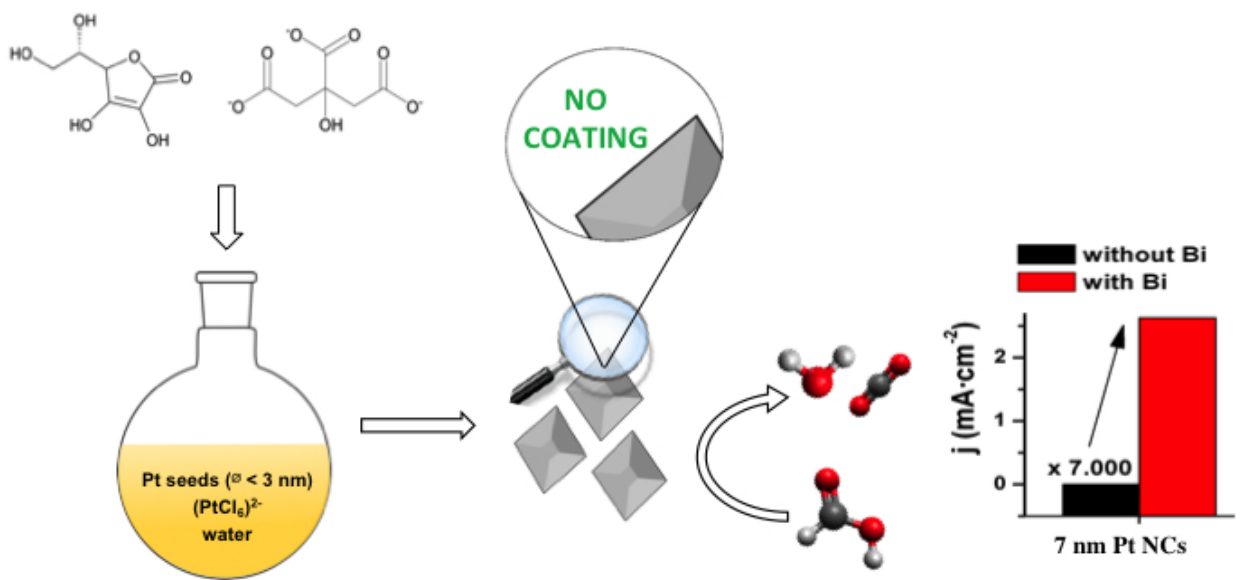

Table Of Contents Graphic

$254 \times 142 \mathrm{~mm}(72 \times 72$ DPI $)$ 